\title{
Nurses' Role in Discharge Preparation for Acute Coronary Syndrome Patients
}

\author{
Azizah Khoiriyati ${ }^{1,2, *}$ Kusnanto Kusnanto $^{3,}$ Ninuk Dian Kurniawati ${ }^{4}$
}

\author{
${ }^{1}$ Doctoral Student, Faculty of Nursing Universitas Airlangga \\ ${ }^{2}$ School of Nursing Faculty of Medicine and Health Sciences Universitas Muhammadiyah Yogyakarta \\ ${ }^{3,4}$ Faculty of Nursing Universitas Airlangga \\ *Corresponding author.Email: azizah.khoiriyati-2018@fkp.unair.ac.id
}

\begin{abstract}
Introduction: Patients with post hospitalized heart attack often feel insufficiently ready for the hospital to home transition. Problem focused on patients and health care providers can contribute to the significant residual risk seen in patients with acute coronary syndrome. Therefore, nurses could play an integral role in ensuring suitable care. The aim of this research was to investigate the role of nurses in patients with for acute coronary syndrome preparing for discharge. Method: An exploratory qualitative research design with phenomenology approach was used in the study. Data collection used semi-structured interviews with 15 nurses form 2 private hospitals in Yogyakarta. Data were collected from March to June 2020 with face to face interview and telephone call. Result: There are 5 themes of the role of nurses which are obtained from the result of the qualitative analysis consisting of: (1) Educator; (2) Care provider; (3) Motivator; (4) Collaborator; (5) Communicators. Conclusion: The roles of nurses in the care of patients with post acute coronary syndrome are as an educator, care provider, motivator, collaborator and communicator for both ACS patients and their families.
\end{abstract}

Keywords: Acute coronary syndrome, Discharge preparation, Nurses' role

\section{INTRODUCTION}

Acute coronary syndrome (ACS) is an elevated morbidity and mortality disorder [1]. There is an elevated long term risk of repeated cardiovascular problems in patients with ACS. As the number of related comorbidities, frequently seen in patients presenting with $\mathrm{ACS}$, rises, this risk continue to increase [2]. The risk of recurrence, especially in the first year [3], is still high. In the United states, the occurrence of myocardial infarction was 805.000 in 2018, where 605.000 were new cases and 200.00 (25\%) were chronic cases [4]. The highest incidence of cardiovascular disease in Indonesia was coronary heart disease [5].

There are still differences in the treatment of ACS patients, from admission to hospital discharge and subsequent long-term follow-up care at all stages. The disease, patients and health care provider centered problems can lead to these care gaps and contribute to the significant residual risk seen in ACS patients. For instance, if patients are discharge without the awareness of their illness and or their drug regimen, they may neglect to fill in their medication [2]. Patients with post hospitalized heart attack often feel insufficiently ready for the hospital to home transition [6]. Discharge from the hospital is often accompanied by inadequate information [7]. Data analysis used open code software based on thematic analysis [11]. By good interaction with participants, the credibility of the results is built. The member check is used to compare the suitable of ideas obtained from data with the opinions of the participants [12]. An external examiner who was acquainted with qualitative research was evaluated for suitability. Peers are presented with extracted codes and categories, and their suitability is controlled and verified. The discharge information requirements are highly significant for most ACS patients [8].

In ensuring suitable care, nurses could play an integral role [9]. The role and scope of the role of specialist nurses in the diagnosis and treatment of NSTEMI patients has been less well-defined. Few studies have assessed the wider function of nurses with specialist chest pain or ACS [10]. When the patient is moved to the cardiology ward from the coronary care unit, post ACS nurse practitioner care program begins. In the ward under the direct supervision of the attending cardiologist, the nurse practitioner is responsible for medical treatment. Clinical rounds and order management involve supervising nurses and educating patients and families about the management of their disease. The function of ACS nurses varies in order to bridge treatment across division and across inpatient and outpatient facilities. There are complexities in providing care services with complex systems with high demands, high service demands, priority care, professional and organizational boundaries [10]. The aim of this research was to investigate the role of nurses in patients with acute coronary syndrome preparing for discharge. 


\section{METHOD}

\subsection{Research Design}

This research was a qualitative study with a phenomenology approach to explore the role of nurses on acute coronary syndrome patients.

\subsection{Participant}

Participants in this study were nurses in the Intensive Cardiac Care Unit, adult patient care wards and outpatient clinics in two private hospitals in Yogyakarta. The selection process of participants used a purposive sampling technique. The participant criteria included were: (1) nurses with work experience of more than 2 years, (2) nurses who are permanent employees in the hospital. There were 15 participants who participated in this study

\subsection{Data Collection}

Data collection used semi-structured one-to-one interviews through a face to face interview and phone call from March to June 2020. All of the interviews were recorded using audio recording and then transcribed.

After completing the interview, the interview transcript was prepared and its suitability was checked with the recorder. The researchers checked the recorder and transcript repeatedly to ensure the suitability of the data.

\subsection{Data Analysis}

Data analysis used open code software based on thematic analysis [11]. By good interaction with participants, the credibility of the results is built. The member check is used to compare the suitability of ideas obtained from data with the opinions of the participants [12]. An external examiner who is acquainted with qualitative research evaluated the suitability. Peers were presented with extracted codes and categories, and their suitability is controlled and verified.

\subsection{Ethical Consideration}

The Health Research ethics committee team of the Faculty of Nursing, Universitas Airlangga, accepted this study in letter no. 1915-KEPK. Both participants had obtained an explanation and confirmed that by signing informed consent, they were prepared to decline or participate. In this paper, all participant names have been deleted for secrecy. The researchers record and report the entire research process to allow further research by others so that this research can be relied on.

\section{RESULT}

The characteristics of the participants in this study consisted of 6 male and 9 female participants. The work experience of participant ranges from 3.5 years to 26 years. All participants have a bachelor's degree. The following is a table of participant characteristics (Table 1). There are 5 themes of the role of nurses which are obtained from the results of the qualitative analysis consisting of: (1) Educator; (2) Care provider; (3) Motivator; (4) Collaborator; (5) Communicators

\section{Theme 1: Nurses as Educators}

This theme describes nurses during the process of patients' discharge as an educator for the patient and the family. Providing education to patients and families is carried out while the patient is in the treatment process and when the patient returns. The provision of education includes the education about activities, how to care at home, the importance of taking medication regularly, dietary, how to avoid stress, regular control, stopping smoking and the signs and symptoms of a heart attack. Here is an example of a quote from a participant:

"We provide patient education if the symptoms worsen during activity. If there is a cold sweat or maybe a repeat attack, it is necessary to go to health services for examinations such as ECG recording or at least to health services so that it can be ascertained that it is gastric disease or recurrent attacks" (Participant 1).

\section{Theme 2. Nurses as care providers}

This theme illustrates the process of preparing for the discharge of post acute coronary syndrome patients. This theme illustrates that in the acute coronary process, nurses act as nursing service providers. The nurse performs an assessment of the patient, formulates a nursing diagnosis, prepares a nursing plan, intervenes by performing various procedures for the patient, monitoring during treatment, and conducting an evaluation. The following are excerpts from participants: 
Table 1. The Characteristic of the Participant

\begin{tabular}{|c|c|c|c|}
\hline Number of participant & Age (year) & Sex & Work experience (year) \\
\hline 1 & 48 & Female & 10 \\
\hline 2 & 34 & Male & 5 \\
\hline 3 & 29 & Male & 4 \\
\hline 4 & 35 & Male & 7 \\
\hline 5 & 28 & Female & 4 \\
\hline 6 & 31 & Male & 26 \\
\hline 7 & 28 & Female & 22 \\
\hline 8 & 49 & Female & 25 \\
\hline 9 & 29 & Female & 25 \\
\hline 10 & 45 & Female & 25 \\
\hline 11 & 48 & Female & 29 \\
\hline 14 & 48 & Female & 25 \\
\hline
\end{tabular}

"... Observed clearly for hemodynamic status, then vital sign, then clinical patients still have chest pain or not ..." (Participant 11)

"To prepare for our return home, we usually examine who is closest to the house. Who accompanies..... Then we teach the education ... "(Participant 5)

\section{Theme 3. Nurse as a motivator}

This theme illustrates that nurses act as motivators in the healing process in post-ACS patients, including lifestyle changes, which include motivation to mobilize, motivation to quit smoking, adhere to the diet, motivation to adhere to a control schedule, and routine taking medication. In addition, motivation is not only applied to the patient but also to the patient's family to provide support both during hospitalization and at home. The following are excerpts from participants:

"... if the motivation for mobilization is after post catheterization. Some are afraid to mobilize, but we are motivated to mobilize. " (Participant 2).

\section{Theme 4. Nurse as collaborator}

Nurses act as collaborators, from various health professions from doctors, nutritionists, and pharmacists. In addition, nurses also collaborate with non-health professions, namely clergy. The nurse will contact the hospital clergy if, based on the assessment results, there are patients who really need intense assistance from the clergy.
"... we confirm to nutrition. So later the nutritionist will also come to deliver education on the diet." (Participant 11).

\section{Theme 5. Nurses as communicators}

This theme describes the role of nurses as communicators, especially to patients and families. Communication by nurses is done intensely during the treatment process. The nurse communicates, such as when giving interventions to patients, as well as during education. There are things that happen to the patient that the nurse communicates to the family. Some patients who have a low educational background and are elderly have their own difficulties in communicating with patients. Some patients also have an indifferent attitude towards their condition and have low adherence, which requires better communication approaches and strategies. The following are excerpts from participants:

"We communicate with each other, but we ask the patient, the point is what is needed to tell us ..." (Participant 9).

\section{DISCUSSION}

In this study, the role of nurses in the care of post ACS patients is as an educator for both ACS patients and their families. This is in line with previous studies that show that nurses have an educator role. Compared to the medical profession, the education provided by nurses is more felt by patients [9]. Education is a process by which information is gained and skills that can lead to changes 
in human behaviour that are required to preserve or to improve health [14].

Health education-related interventions for the ACS patients refer to planned activities or programmes. These includes modification of behavior, counselling and intervention in teaching [15]. Cardiac rehabilitation nursing education can improve health outcomes and lower the risk of a new cardiac event [14]. To obtain the optimum benefit for eduction, it should include patients, description of the target, evaluation of needs of patients, patients modification behavior towards more regulation of oneself active engagement in decision making, self care production to manage an illness, and potential complication, personal risk factors assessment, implementation of realistic goals, support to adopt a positive attitude towards the disease and alleviate psychological distress [14]. For all categories, medication was in the highest ranking patients reported having high information needs followed by heart structure and function, symptom management, risk factors, diet, miscellaneous, and psychological factors [8].

The role of nurses as care providers in this study starts from assessment, formulating a nursing diagnosis, implementation, and evaluation. In recovery, nurses play a crucial role as they are close to the patients and their families during all the process of disease. Meeting the rehabilitative care needs of patients through knowledge, encouragement, supervision, and affirmation is a matter of great importance for nurses [14]. The learning needs according to the perception of patients, family member of patients and nurses. There should be an accurate assessment to create adequate intervention to meet the learning needs to the patients [16].

The role of nurses in this study is as a motivator for patients and families in the healing process and healthier lifestyle changes. Patients were motivated to changing their lifestyle and contemplating taking their lives in a new direction, adopting a perspective life change, finding meaning in had happened and managing the complication [17-19].

The nurse can have role as a collaborator with other professions in the patient care process and preparing for discharge. In collaborating with both doctors and fellow nurses to treat patients with ACS in emergency unit, nurses also face barriers. Obstacles have been found in assertiveness, autonomy and cooperation in the treatment of ACS patients in emergency departments are three aspects of the collaboration process [20].

The role of the nurse as a communicator is carried out during the patient care process. Communication is carried out through verbal as well as non-verbal. The approach to patients and families is carried out by nurses so that healing targets are achieved. Nurses can use the motivational interviewing as a therapeutic communication method based on the evidence that helps patients better understand. To identify, create, implement, and sustain positive changes in health behaviours and decisions, patients can use their personal resources. It helps patients and nurses [21]. The presence and availability of the nurses for non-verbal and verbal communication created a trustful connection where new knowledge was acquired and motivational strenght was mobilized for life style changes [22].

The strength of this research is the description of the role of nurses in the patient's discharge readiness process. The limitation in this study is that it cannot be generalized. In addition, the research location does not represent the hospitals in Yogyakarta or Indonesia. Suggestions for future researchers is that they need to explore things that support and hinder nurses in the process of preparing for the discharge of post ACS patients from the hospital.

\section{CONCLUSION}

The role of nurses in the care of post ACS patients is as an educator for both ACS patients and their families. The role of nurses as care providers in this study starts from assessment, formulating a nursing diagnosis, implementation, and evaluation. The role of nurses in this study is as a motivator for patients and families in the healing process and healthier lifestyle changes. Nurses can also work in collaboration with other professions in the patient care process and preparing for discharge. The role of the nurse as a communicator is carried out during the patient care process. Nurses can use motivational interviewing as a therapeutic communication method.

\section{AUTHORS' CONTRIBUTIONS}

All authors conceived and designed the study. All authors wrote, read and approved the manuscript.

\section{ACKNOWLEDGMENTS}

The author would like to thank all participants, and the doctoral scholarship from the Ministry of Education and culture of the Republic of Indonesia and Universitas Muhammadiyah Yogyakarta for the financial support.

\section{REFERENCES}

[1] Gibler WB, Racadio JM, Hirsch AL, and Roat TW 2018 Continuum of Care for Acute Coronary Syndrome: Optimizing treatment for ST-Elevation Myocardial Infarction and Non-ST Elevation Acute Coronary Syndrome. 17 :114-138.

[2] Goldman JD, and Harte FM 2020 Transition of care to prevent recurrence after acute coronary syndrome: the critical role of the primary care provider and pharmacist. Postgrad Med $1325: 426$ 432. 
[3] Abu-Assi E, López-López A, González-Salvado V, Redondo-Diéguez A, Peña-Gil C, Bouzas-Cruz N, Raposeiras-Roubín S, Riziq-Yousef Abumuaileq R, García-Acuña JM, and González-Juanatey JR 2016 The Risk of Cardiovascular Events After an Acute Coronary Event Remains High, Especially During the First Year, Despite Revascularization. Rev Española Cardiol (English Ed 69 1 :11-18.

[4] Benjamin EJ, et al. 2018 Heart Disease and Stroke Statistics-2018 Update: A Report From the American Heart Association doi:10.1161/CIR.0000000000000558

[5] Riskesdas 2018 Penyajian Pokok-Pokok Hasil Riset Kesehatan Dasar 2013 (Depkes RI)

[6] Barnason S, Zimmerman L, Nieveen J, Schulz P, and Young L 2012 Patient recovery and transitions after hospitalization for acute cardiac events: An integrative review. J Cardiovasc Nurs 272 :175191.

[7] Lin Y-H, Kao C-C, Huang A-M, Chi M-T, and Chou F-H 2014 Psychometric testing of the Chinese version of the readiness for hospital discharge scale. J Nurs 614 :56-65.

[8] Sz H, Hassan NH, Sin CS, Hwa NC, Siew S, and Maskon O Bin 2018 Patients 'Discharge Information Needs Regarding Acute Coronary Syndrome in Teaching Hospital. 1 :49-58.

[9] Tierney S, Cook G, Mamas M, Fath-Ordoubadi F, Iles-Smith H, and Deaton C 2013 Nurses' role in the acute management of patients with non-ST-segment elevation acute coronary syndromes: An integrative review. Eur J Cardiovasc Nurs 123 :293-301.

[10] Deaton C, Johnson R, Evans M, Timmis A, Zaman J, Hemingway H, Hughes J, Feder G, and Cramer H 2017 Aligning the planets: The role of nurses in the care of patients with non-ST elevation myocardial infarction. Nurs Open 4 :49-56.

[11] Chesnay M De 2015 Nursing Research using Phenomenology (Springer Publishing Company, New York) doi:10.4324/9781003011798-1

[12] Nowell LS, Norris JM, White DE, and Moules NJ 2017 Thematic Analysis: Striving to Meet the Trustworthiness Criteria. Int J Qual Methods 161 $: 1-13$.

[13] Connelly LMBT-MN 2016 Trustworthiness in qualitative research. $256: 435+$.

[14] Kadda O, Marvaki C, and Panagiotakos D 2012 The role of nursing education after a cardiac event. Heal Sci J 64 :634-646.

[15] Liu XL, Shi Y, Willis K, Wu CJJ, and Johnson M 2017 Health education for patients with acute coronary syndrome and type 2 diabetes mellitus: An umbrella review of systematic reviews and metaAnalyses. BMJ Open 710 . doi:10.1136/bmjopen2017-016857

[16] Huriani E 2019 Myocardial infarction patients' learning needs: Perceptions of patients, family members and nurses. Int J Nurs Sci 63 :294-299.
[17] Khoiriyati A, Kusnanto, and Kurniawati ND 2019 Experiences of recovery from acute coronary syndrome: A systematic review. Indian J Public Heal Res Dev 108 :2813-2816.

[18] Falun N, Fridlund B, Schaufel MA, Schei E, and Norekvål TM 2016 Patients' goals, resources, and barriers to future change: A qualitative study of patient reflections at hospital discharge after myocardial infarction. Eur J Cardiovasc Nurs 157 :495-503.

[19] Kristofferzon ML, Löfmark R, and Carlsson M 2008 Managing consequences and finding hope Experiences of Swedish women and men 4-6 months after myocardial infarction. Scand J Caring Sci 22 :367-375.

[20] Wihastuti TA, Rahmawati I, Rachmawati SD, Lestari YC, and Kumboyono K 2019 Barriers of Nurse Collaboration for the Care of Acute Coronary Syndrome Patients in Emergency Departments: A Pilot Study. Open Nurs J 13 :60-65.

[21] Debbie Bershad, BSN, RN C 2019 Motivational interviewing_ A communication best practice American Nurse. Motiv interviewing A Commun best Pract 149 :96-98.

[22] Liljeroos M, Snellman IM, and Ekstedt MH 2011 A qualitative study on the role of patient-nurse communication in acute cardiac care. J Nurs Educ Pract 11 . doi:10.5430/jnep.v1n1p17 